This is a self-archived - parallel published version of this article in the publication archive of the University of Vaasa. It might differ from the original.

\title{
Civic voice in multimodal news narratives
}

Author(s): Tuunanen, Yrjö; Hirsto, Heidi

Title: $\quad$ Civic voice in multimodal news narratives

Year: $\quad 2018$

Version: final draft (post print, aam)

Copyright John Benjamins Publishing

\section{Please cite the original version:}

Tuunanen, Y. \& Hirsto, H., (2018). Civic voice in multimodal news narratives. In: Patrona, M. (ed) Crisis and the Media : Narratives of crisis across cultural settings and media genres, 205-230. https://doi.org/10.1075/dapsac.76.10tuu 


\title{
Chapter 9
}

\section{Civic voice in multimodal news narratives}

Yrjö Tuunanen and Heidi Hirsto

\begin{abstract}
In this chapter, we examine civic voice in visual news narratives about the economic crisis. We discuss how the possibility of voice may be linked to particular practices in multimodal news discourse. We analyze captioned stock photo galleries depicting antiausterity protests in Greece, and demonstrate how these narratives create a simplified grouping of actors with narrative necessity and a loose connection to the "real". Thus, they reproduce the dominant master narrative juxtaposing financial pragmatism with emotioned expressions of civic voice. We discuss how this kind of doing the crisis tends to muffle civic voice and naturalize the establishment story of the crisis. We conclude by proposing how multimodal online news reporting might better realize their potential in mediating civic voice.
\end{abstract}

Keywords: Multimodal news narration, visual news, financial crisis discourse, binary constructions, civic voice, agency, critical multimodal narrative analysis, narrative structure, narrative necessity, editorial reality.

\section{Introduction}

The sovereign debt crisis in Greece has remained acute for several years despite continuing bailout and austerity measures. As the crisis has prolonged, representatives of the main institutions involved in the bailout process have started to attribute responsibility in innovative ways. For example, on March 5th 2015, European Commission Vice-President Jyrki Katainen remarked in an interview by the Finnish Broadcasting Company Yle (YLE 2015), that citizens of Greece have asked for help from, and made promises to other citizens from around Europe, and that they are thus partly responsible for the national debt burden. The statement is remarkable in that it obligates ordinary Greeks, along with the government, in the bailout process. 
This chapter examines the preconditions of civic voice and civic culture in online news about the Greek debt crisis. We start with the notion that the prolonged "state of emergency" (Žižek 2010) of the financial markets has created major challenges for members of the public for practicing one's full economic, social and cultural rights. With international debtors imposing strict conditions on nation states, it has become ever more difficult for citizens to influence the conditions of their own everyday lives. Moreover, while the journalistic media ideally play an important role in facilitating critical consciousness, mediating practices, and offering preconditions for deliberative citizenship, it seems that in the current mainstream media reality, it is difficult for citizens to be able to express arguments with a voice that counts. It has been argued, for example, that the prevailing debt crisis news discourse is largely built on simplified dualistic master narratives - based on a dichotomy of "neutral financial pragmatics" versus futile, emotionalized anti-austerity movements (Žižek 2010) - that are likely to narrow down the possibility and scope of civic voice.

Our study explores the problematics and potential of civic voice in visual news narratives. We draw on Couldry's (2010:8) definition of voice as a form of reflexive agency that precedes action and includes responsibility for stories told. Thus, voice is distinctly linked with particular aims and intentions; charged with an objective, a suggestion or a demand for readjusting prevailing practices or policies. Moreover, voice as value is related to enabling and supporting voice, that is, valuing the assets, conditions and platforms that respect voice as a process (ibid. 2). In this way, voice is linked to civic culture, which ideally is, according to Dahlgren (2000:1), collective meaning making that "entails a capacity to see beyond the immediate interests of one's own group." Voice thus deals, above all, with public-minded expressive and participative action oriented to enhancing common well-being in the society.

During the era of expansion of online news video (Pew Research Center 2014), this study focuses on another prevailing visual genre of online news discourse: captioned stock photo galleries and slide shows. The study analyzes photo galleries as an emerging journalistic practice where particular social and material features intertwine to create particular conditions of possibility for representing and mediating civic action. In this way our study illustrates "the constitutive and enabling role of non-human actors" such as technologies and formats in "doing crisis" (see De Rycker, this volume). 
From the perspectives of narrative analysis and multimodal discourse analysis, the article discusses how the organization of visual and verbal components in such visual news texts may enable or muffle civic voice. We evaluate how the selection and orchestration of semantic resources may either create predisposition for a particular interpretation of the story, that is, create narrative necessity and seduction (Bruner 1991:4, 9) or, instead, enable narrative transparency through applying mixed modes of framing (Iyengar 1991:14). The main question that we address in this chapter is: How do the discursive features and narrative structures of the captioned slide shows and picture galleries reinforce or challenge the mainstream master narratives of the Greek debt crisis, and where and how do the citizens as characters or participants stand in these settings?

Our close analysis of two visual news texts reveals discursive practices that reproduce and accentuate the binary constructions inherent in the dualistic master narrative of the financial crisis. The analysis shows that, typically, captioned slide shows and picture galleries are built as sets of intensively dramatic stock photo images, depicting decisive "pregnant moments" that offer "a window on the preceding and following actions" (Ryan 2014:3). These kinds of charged and narratively open visual components seem to be ideal constituents for creating narrative intensity and indifference to extra-narrative reality (Bruner 1990:44). They tend to create "editorial reality" where the Greek debt crisis is simplified into binary constructions, such as morality and brinkmanship, order and chaos, and reason and rage, which refer to the prevailing dualistic master narrative of the crisis.

Furthermore, our analysis shows how the practice of melting decontextualized photographs into a whole that implies narrative coherence tends to trivialize the roles and reasoning of citizens, and reduce the motives and forms of civic action into mere narrative elements and to a flow of constituent events driving the story forward (Abbott 2008:22). This kind of narrative coherence tends to unify citizens, assimilating diverse groups of demonstrators with the violent, simple-minded front line mobs. In the visually intensive news narratives, civic voice and the objectives and motivations of civic movements are thus easily obscured, ignored, or neglected. These narratives depict civic action mainly as pointless expression of anger and frustration, while dismissing any reference to the malfunctions of the society, or suggestions to rethink and rearrange the policies practiced during the financial turmoil. 


\section{Theoretical framework}

\section{Binary master narratives in the neoliberal project}

Narrative has been widely seen by scholars "as a discourse that conveys a story" (Ryan 2014), and as an essential mode for human motivation, a way to make sense of the world and one's life (Page 2011:6). Apart from the (1) individual narratives that we draw on when building our own life and identity, the discursive palette of storytelling includes, (2) public narratives of wider social circulation, (3) conceptual narratives formulated by researchers, as well as (4) meta- or master narratives, such as "the epic dramas of our time: Capitalism vs Communism, the Individual vs Society" (Somers \& Gibson 1994:61-63).

The point of departure of this study is the prevailing binary master narrative of financial crisis talk (Žižek 2010; Tsoukala 2013). In this master narrative, global market forces and institutions are challenging national socio-economic policies and demanding structural reforms based on allegedly neutral "financial pragmatics". In mainstream news media, such "de-politicized naturalization of the crisis" (Žižek 2010), together with its indispensable solutions, has become the dominant component of the binary master narrative, the "establishment story". The other stories, in turn, have often been represented in the news media merely as futile, antagonistic points of view against the inevitable.

Thus, during the past few years of the debt crisis, Greece and the Greeks have been defined, for example, as the sick men among healthy other Europeans, as the risky gamblers compared with the moral others, as the lazy grasshoppers compared with the hard-working ants, as Zeus abducting Europa or as "the young black man of Europe" (Lehman 2015) compared with the adult and responsible other Europe.

The prevailing crisis and bailout master narrative is rooted in the broader project of neoliberalism, which generalizes the advantages of markets, tends to ignore the value of other modes of social and economic organization (Couldry 2010:11), and "normatively constructs and interpellates individuals as entrepreneurial actors in every sphere of life" (Brown 2005:42). As Couldry notes, there is little room for voice and agency in the neoliberal project, in that neoliberalism "does not require the exchange of narratives between reflexive, embodied agents" as voice does (Couldry 2010:11). 
Rationalistic and normative neoliberalism ignores, or rather, repudiates voice. It reaches economic, political, social and cultural life through "extending and disseminating market values to all institutions and social action" (Brown 2005:40) and expecting the public, society and national institutions to support the functioning of the free markets. The resulting oxymoron of "neoliberal democracy" (Couldry 2010:52), the impossible fit of democracy and neoliberalism, seems to be reflected in the discursive setting, where ordinary Greeks, along with the government, are obligated in the bailout process, but without having an opportunity to have a voice that counts.

Cultural master narratives and narratives more generally, relate to social and political realities in complex ways. Narratives are always to some extent "governed by convention and 'narrative necessity' rather than by empirical verification and logical requiredness" (Bruner 1991:4-5). Hence, narratives are characterized by partial independence from or indifference to extralinguistic reality. This makes the narrative approach particularly valid and viable for analyzing the "doing of crisis": the ways in which multimodal news narratives represent and position actors as participants in a crisis, transmitting or ignoring their arguments and motivations as well as the settings and flows of events within which they act.

\section{Civic voice and agency}

In this study, we regard voice as a form of reflexive, public-minded agency (Couldry 2010). In our view, civic agency necessarily includes the possibility of voice also in the economic domain, i.e. the possibility to participate in economic discourses and practices in reflective, critical, socially embedded and collective ways. From this perspective, we regard the anti-austerity demonstrations as an example of reflexive agency: an attempt of public-minded citizens to gain voice in a domain largely dominated by the voice-denying rationality of neoliberalism. News reports, in their turn, can be understood as discursive recontextualizations of these civic actions (Van Leeuwen, 2008; De Rycker, this volume).

In narrative studies, agency may refer to two things. First, it can refer to characters, intelligent agents with reasoned motives and emotions, making things happen (Abbott 2008:131) and playing a central part in building events within a world of the narrative discourse. Apart from that, as Herman remarks, agency is essential at the level 
of telling the story, "affecting who gets to tell what kind of story in what contexts" (Herman 2007:275).

In the first sense of agency, this study traces civic voice and agency as elements that may be present or absent, enacted or suppressed, within the news narratives of antiausterity demonstrations. Our analysis examines what happens to voice when civic action is recontextualized as a news story and citizens become characters in a narrative.

In the second sense of agency, we assess the news media as storytellers and gatekeepers, and as facilitators of civic culture. According to Couldry (2010), voice as a socially grounded process, the sharing of stories, depends on shared social and material resources, such as verbal and visual language and sites of communication. Voice as value, in turn, concerns supporting and enabling processes and conditions of voice. Overall, then voice is an embodied process and requires a material form (Couldry 2010:3) and platforms to be exposed.

The role of the news media, in the process of valuing and enabling voice, lies not only in providing insights into economic events and mechanisms but also in offering preconditions for reflexive civic participation more broadly. Ideally, the media should work as an arena and a vehicle of civic culture. The concept of civic culture, as defined by Dahlgren (2009:102-103), refers to the conditions and forms of civic agency, and the ability and will of individuals to participate in discussions and activities in the society. In the concluding section of this chapter, we reflect upon the practices of multimodal news narration with reference to the six preconditions of civic culture: knowledge, values, trust, spaces, practices and skills, and identities (Dahlgren 2009:108).

\section{Critical multimodal narrative analysis}

The empirical aim of this study is to add to our understanding of the ways in which narrative meaning making processes in visual online news texts may represent and facilitate, or, conversely, downplay civic voice. Towards this end, we analyze captioned stock photo galleries and slide shows within a framework of "critical multimodal narrative analysis". The framework is built on the principles and elements of critical discourse analysis, multimodal discourse analysis, and narrative analysis. 
Critical discourse analysis studies:

the way social power abuse, dominance, and inequality are enacted, reproduced, and resisted by text and talk in the social and political context. With such dissident research, critical discourse analysts take explicit position, and thus want to understand, expose, and ultimately resist social inequality (Van Dijk 2001:352).

In this study, the critical perspective guides the question setting and the interpretation of findings. It directs attention especially to how the dominating master narratives of the economy are manifested in and reproduced through the visual news narratives.

Multimodal discourse analysis, in turn, is concerned with the meaning potential of different semiotic resources (in our case, written text and visual imagery) in multimodal texts, the interaction of semiotic choices, and the semantic expansions or contradictions that occur in this intersemiosis (Matthiessen 2006). We regard the captioned photo gallery as a multimodal genre, where the selection and organization of semiotic resources is guided by both social (e.g. journalistic) and material practices. Our analytical focus lies on how the organization of multimodal texts bears on the representation of citizens, as well as on readers' interpretative possibilities.

In analyzing the narrative structures and features of the texts, our analytical lens is based on Bruner's $(1986,1991)$ ideas of narrative and paradigmatic modes of organizing perceptions of the world; Ryan's $(2007,2014)$ model of four constituents of a story; and Iyengar's (1986) distinction of episodic and thematic framing in visual news stories.

Bruner proposes, from the standpoint of psychology, two distinct, though complementary modes of human cognition, two "ways of ordering experience, of constructing reality" (1986:11). First, the narrative mode of thinking addresses the structure and power of compelling stories. It concerns causality constructed through a diachronic, sequential flow of events with intelligent agents. The second, argumentative or paradigmatic mode of reasoning, concerns general causes and evidence aiming for the logical extension of particulars to verified observations, explanations and abstractions. 
Ideally, it "leads to good theory, tight analysis, logical proof, sound argument, and empirical discovery guided by reasoned hypothesis" (1986:13).

In our study, we use Bruner's ideas to expand on Ryan's (2007, 2014) model, which defines a narrative in terms of four constituents: a spatial, a temporal, a mental, and a formal/pragmatic constituent. The spatial component concerns the drafting of scene, setting, spaces, characters and overall groupings. The temporal constituent addresses the flow of events or happenings, or the plot. The mental constituent concerns mental states, motives and goals of intelligent agents and thus ideally explains and justifies their actions. Eventually, the formal and pragmatic constituent advocates closure and a meaningful message, thereby commenting on the meaning of the story.

Narrative form binds its individual elements into a solid account of series of events, building a story that typically has a pattern with beginning, middle, and end, as well as highlighted "turning points" (Block 2008:226). Overall, "the sequence of its sentences, rather than the truth or falsity of any of those sentences, is what determines its overall configuration or plot" (Bruner 1990:44). Hence, narratives are predominantly versions of reality: they establish "verisimilitude" rather than truth (Bruner 1986:11).

In the case of visually affective news stories, such as captioned stock photo slide shows, this inherent nature of narrative raises two analytical questions. Firstly, to what extent does the narrative form lead to what can be called "meaning contamination"; specifically, how do the highlighted elements that constitute "turning points" of the narrative, affect the meaning potential of neighboring elements and the narrative as a whole? Secondly, to what extent does the narrative form create inside-the-media perspective (Olsson \& Nord 2015) or "editorial reality" as opposed to enabling narrative transparency that would acknowledge the messy reality of the crisis and give voice to the actors depicted?

As a final analytical tool, we use Iyeangar's notions on television news framing, which resonates productively with Bruner's modes of reasoning. According to Iyengar (1991:13), television news reporting on political issues can generally be divided into two distinctive approaches. Episodic framing refers to illustrative news stories, which focus on particular incidents or individuals and "case studies" depicting specific events. Thematic framing, in turn, refers to news texts which present "collective or general evidence", such as analytical reports on series of events or phenomena, or on "public issues in some more general and abstract context" (1991:14). In practice, television news 
reports are rarely purely episodic or thematic, but rather, mixed modes where one of the frames predominates (1991:18).

In the context of financial crisis news, both episodic and thematic framing arguably have their role in transmitting public-minded civic action in the media. Episodic visual news texts that represent civic participation such as mass demonstrations and street protests, are meant to be noticed as "on-the-scene-coverage of hard news" (Iyengar 1991:14). However, as Iyengar (1991:14 -15) notes, episodic news coverage of demonstrations and protests typically focuses on specific acts of protest rather than on the issues or reasoned arguments that gave rise to them. Therefore, it may be expected that a thematic or a mixed framing might have heightened potential in supporting and valuing civic voice, and motivating civic participation.

\section{Research material and the analytical process}

Our research material consists of two captioned stock photo galleries, which report on demonstrations opposing the austerity measures in Athens, Greece, in June and October 2011. They were published on the websites of the New York Times and the Guardian. Semantically, the New York Times labels these kinds of news texts as slide shows, whereas the Guardian calls them picture galleries, thereby referring more to collections of visual images than narrative visualizations.

The New York Times slide show, titled "Clashes as Greek government passes austerity measures", contains ten pictures organized in a left-to-right layout which can be scrolled by clicking arrow symbols. The Guardian picture gallery, titled "Violence erupts as Greece strike begins - in pictures", consists of twenty pictures, organized in a top-down layout.

Regarding verbal messaging, both of the news texts consist of headlines (in the Guardian gallery a subheading as well), credits to photographers and stock photo agencies, with brief captions along with each image, describing the scene depicted in each photograph.

First, we evaluated the overall narrative and visual structure of the galleries, including layout and the ordering of elements to construct narrative flow. Second, we identified the turning points of the narratives, i.e. the highest points of the story conflict (Block 2008:226) leading the development of the story over the climax into the 
resolution, proposing the essential narrative causalities, with a limited amount of possible outcomes of the narrative as a whole (Bordwell and Thompson 2001:69-70). Third, we examined potential processes of meaning contamination by interpreting individual visual components in relation to their neighboring images and the overall message of the narrative. Then, we interpreted the narratives in terms of Ryan's (2014) constituents of a story, focusing on how the relative emphasis of these components affected the representation of civic activity and the possibility of civic voice. Finally, we evaluated how the visual news texts were inclined to support episodic or thematic framing (Iyeangar 1991), and to enable paradigmatic versus narrative modes of reasoning (Bruner 1986).

\section{Analysis of the two visual news narratives}

\section{“Clashes as Greek government passes austerity measures”, the New York Times}

The narrative organization of the New York Times slide show is based on a diachronic structure and a sequential flow built by the horizontal, left-to-right (indicated by arrow buttons) organization of ten photographs. The news narrative as a whole has a classical structure with beginning (image 1-2/10, the Greek parliament backing the austerity package, while demonstrators protest outside the Parliament building), middle (3-8/10, demonstrations turn into clashes and battles between protesters and police officers), and end (images 9-10/10, the streets are on fire, the protesters stand behind flaming barricades and, eventually, the protesters flee).

The conceptual scene of the slide show is the binary construction within democracy in Greece, depicting citizens on the one side, and governmental actors on the other side. In this case, political decision makers are symbolically visible in one of the pictures, (image 1/10), in an overview of the Parliament hall, which may be interpreted as an iconic picture referring to an idea of established, democratic decision making, rather than depicting individual politicians. The caption of the image 1/10 draws the starting point of the narrative: “The Greek Parliament backed Prime Minister George Papandreou's bitterly contested package of austerity measures on Wednesday, clearing the way for crucial international lending to stave off default over the summer." 
The characters, groupings and identities of the narrative are (1) the citizens as demonstrators, and as rioting protesters confronting riot police, (2a) the legislators in the Parliament voting for the austerity measures, and (2b) their "representatives" on the street level, riot police, who "cordon off streets near Parliament to ensure that protesters did not block legislators' access to the building, with 5,000 officers on the job" (caption, 3/10). The setting of the groupings is the following: the decision makers are voting for the bailout deal and the austerity measures, whereas the indignant citizens are demonstrating at Syntagma Square, and in the streets nearby the Parliament, the visual spatial scene of the narrative. The main spaces drafted in the narrative are the streets of Athens, emphasizing the street level as the main stage for civic participation.

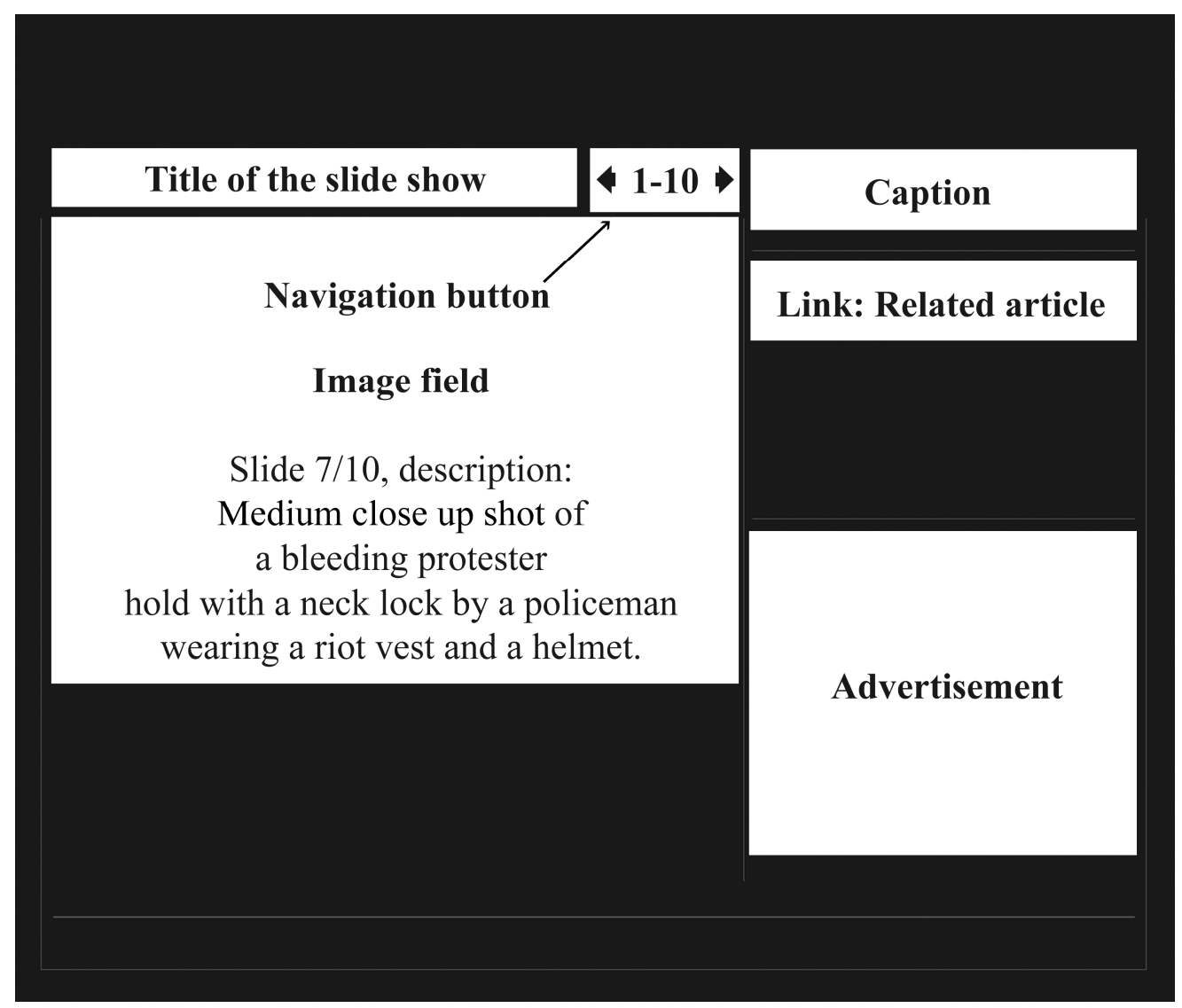

Figure 1. Layout structure of the slide show by the New York Times, image 7/10.

The turning point of the narrative is visualized in images 6-7/10. In image 6/10, the protesters are falling down to the pavement, losing the battle against the overwhelming, well-equipped riot forces. In image 7/10, “A bleeding demonstrator”, is “detained by a police officer" (caption, 7/10) - an event of the day depicted by many 
different photojournalists and images circulated widely by the mainstream media. This image, the "neck locking of civic resistance" both visualizes and symbolizes the power structure of the main binary construction of the narrative: authority and resistance, order and chaos, or rather, disobedience and reorder.

The turning point paves the way to the end of the threefold structure of the news narrative. In the end, riot police take over as the caption of the image 10/10 describes how "protesters rushed into a train station as they fled from tear gas" and frames the closure of the news narrative: after the painful, political decisions, civic anger erupts into violence, which is then suppressed by the police by making the protesters flee. The closure of the news narrative defines the power structure of the binary construction of the story told. Together with the strong narrative as a whole, we argue, the closure creates retrospective meaning contamination by creating an atmosphere of desperate and useless civic resistance against the overwhelming representatives of law and order.

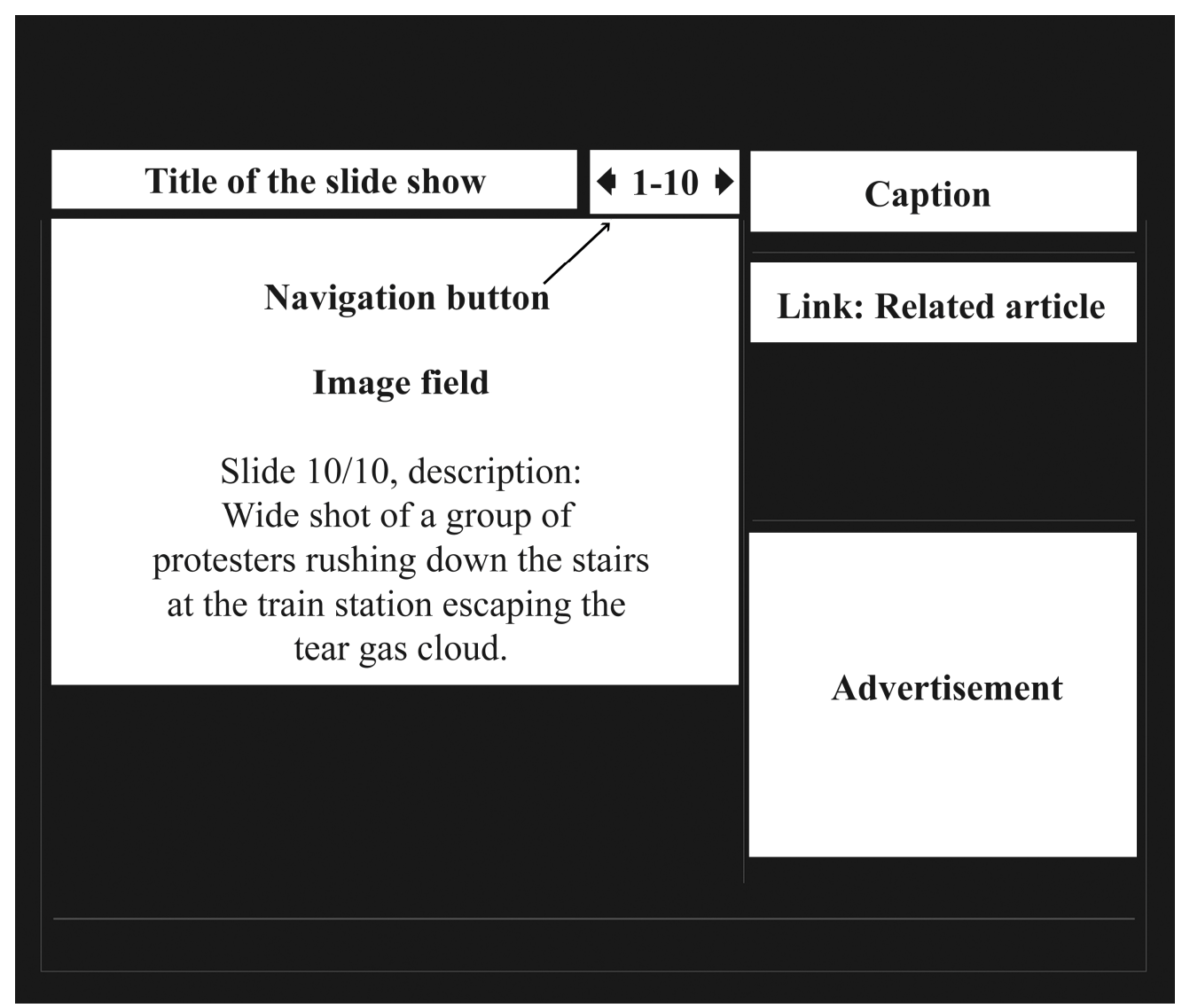

Figure 2. Layout structure of the slide show by the New York Times, image 10/10. 
The narrative provides little clues as to the motivations and reasoning of actors. Instead, the mental constituent of the story strongly emphasizes the emotional mode of the citizens participating in demonstrations and protests. However, even though moral emotions such as anger and indignation are typically based on complex cognitivecultural understandings and interpretations of political issues (Goodwin, Jasper \& Polletta 2007), the text does not refer to any such connection. Furthermore, there are no visual or verbal elements describing the circumstances of the citizens who participate in the street-level activities, nor any indications of the diversity of the citizens participating in demonstrations, protests and violent riots. The captions lack any information on the arguments expressed in the banderoles or slogans chanted in Greek. In the visuals, several violent protesters and police officers are disguising their identity, police officers with their shields, helmets and gasmasks, and hooded rioters wearing respiratory protectors.

Through these narrative choices, the slide show emphasizes the violent confrontation between two opposing groups, creating even surreal visions of street protesters and the police surrounded by flames and orange gas clouds. The affectively biased mental constituent of the narrative results in a closure that is built on a vision of furious rioters creating chaos and being suppressed by the police. This vision, which emerges as the formal and pragmatic constituent of the narrative, offers the simplified binary construction of chaos and order, reason and rage, as the core meaning or message of the story.

The analysis of the news story indicates that the horizontal, left-to-right organization of the photo slide show, together with meaning contamination between affective, narratively open and incompletely messaged photographs, support the flow of the plot and the creation of a strong storyworld, which seems to strengthen the binary opposition between citizens and the representatives of authority, the police. Moreover, the classical diachronic, sequential structure with beginning (exposition), middle (conflict), and end (resolution) (Block 2008:222), increases narrative coherence, necessity, and seduction, and tends to build, intentionally or unintentionally, what we call "editorial reality": coherent, self-referential narratives with a high degree of independence from extra-textual reality, where individual images appear primarily as functions of the dramatized whole. 
Such a strong narrative structure seems to not support thematic, analytical approaches or argumentative mode of reasoning, which would encourage a complex understanding of the events and their structural connections. Strong narrativity assimilates various individuals and groups from peaceful demonstrators to angered protesters and violent rioters, into one solid and simplified category. In this way, narrative seduction and necessity cut back representations of civic activity, fog up the diversity of the participating public, and create articulatory cuts by omitting citizens' arguments and muting their voices. The dense temporal packing of the events of the day compressed into a set of ten loosely captioned images leads to a loss of representational density, that is, lack of comprehensive and in-depth description of events reported. The format thus seems to produce low journalistic "resolution" in the sense of offering only a vague analysis and a blurred view on the topic.

"Violence erupts as Greece strike begins - in pictures", the Guardian

The captioned picture gallery by the Guardian, "Violence erupts as Greece strike begins - in pictures", is subtitled, "Anger over new austerity measures and layoffs erupts into clashes outside parliament as two-day general strike begins". The title seems to imply that there is a certain causal relationship between the beginning of the strike and the eruption of the anger over the austerity measures into violent clashes. It also emphasizes the emotionalized nature of the protests.

A close reading of the Guardian gallery of twenty pictures reveals basically, as in the case of the New York Times slide show, a classical threefold structure of a narrative. Nevertheless, the top to bottom layout of the stock photo material in the Guardian news text creates, instead of a flowing plot and a coherent storyworld, more of an account of events, or a collection of impressions by an eyewitness wandering around the city of Athens from dawn to dusk, or rather, to smoke, gas and flames.

The images 1-4 and their captions focus on the implications of the general strike, drawing an early morning landscape of a desolated city with closed shops in the city center and check-in desks at the airport, abandoned streets, filled with piled-up, uncollected rubbish. The main body of the picture gallery, images 5-17/20, begins with a picture of demonstrators in front of the Parliament building. In the foreground is a male demonstrator with a white theatre mask over his face, wearing a sweater with black and 
white stripes and a number plate, referring to the stereotypical identification pictures of prisoners. The caption describes in short what is seen in the visual image: "A masked demonstrator stands in front of the Greek parliament." Behind him, there is a chain of demonstrators with red flags in front of the parliament building.

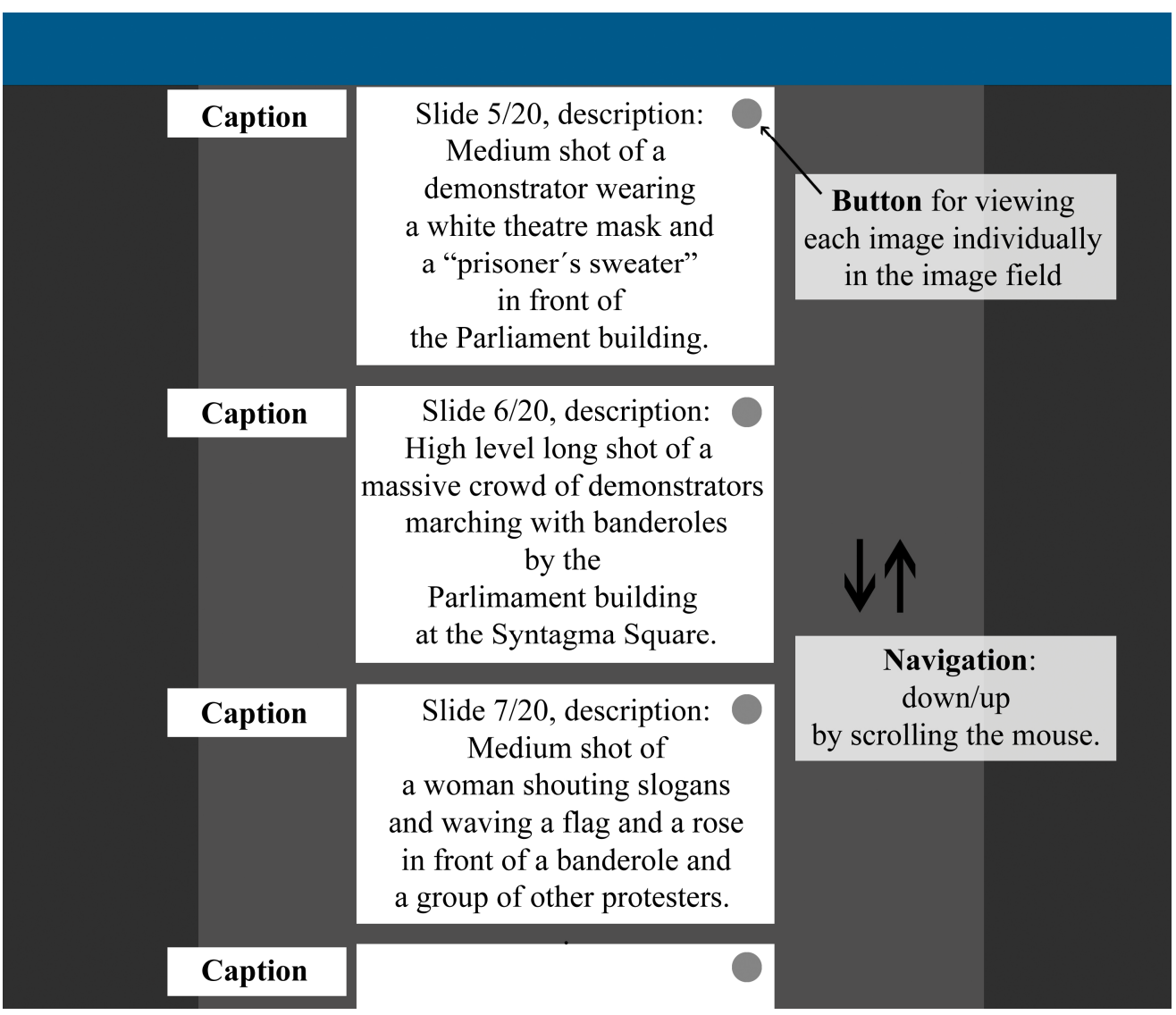

Figure 3. Layout structure of the Guardian picture gallery, images 5-7/20.

During the flow of events in the middle part of the gallery, the demonstrations turn gradually into riots, with images focusing more and more on individuals confronting the riot police. The third part, the last three images of the gallery, draw a landscape of the city of Athens filled with gas, smoke and flames. By the end of the day, there is an irreal, exceptional, almost war-game-like atmosphere. Young rioters, with their covered faces, helmets, gas masks, unidentifiable characters, are bustling on the pavement, more like a species of their own, or as aliens, vandalizing the city. In the last image of the picture gallery, image 20/20, a rioter, as a black silhouette against the flames, is fully unidentifiable. He is walking with big firm steps, perhaps ready to put his next target in fire. The caption, defines: "A man walks past a burning building as the demonstrations escalate." The closure of the picture gallery seems to leave the city in flames, in chaos. 


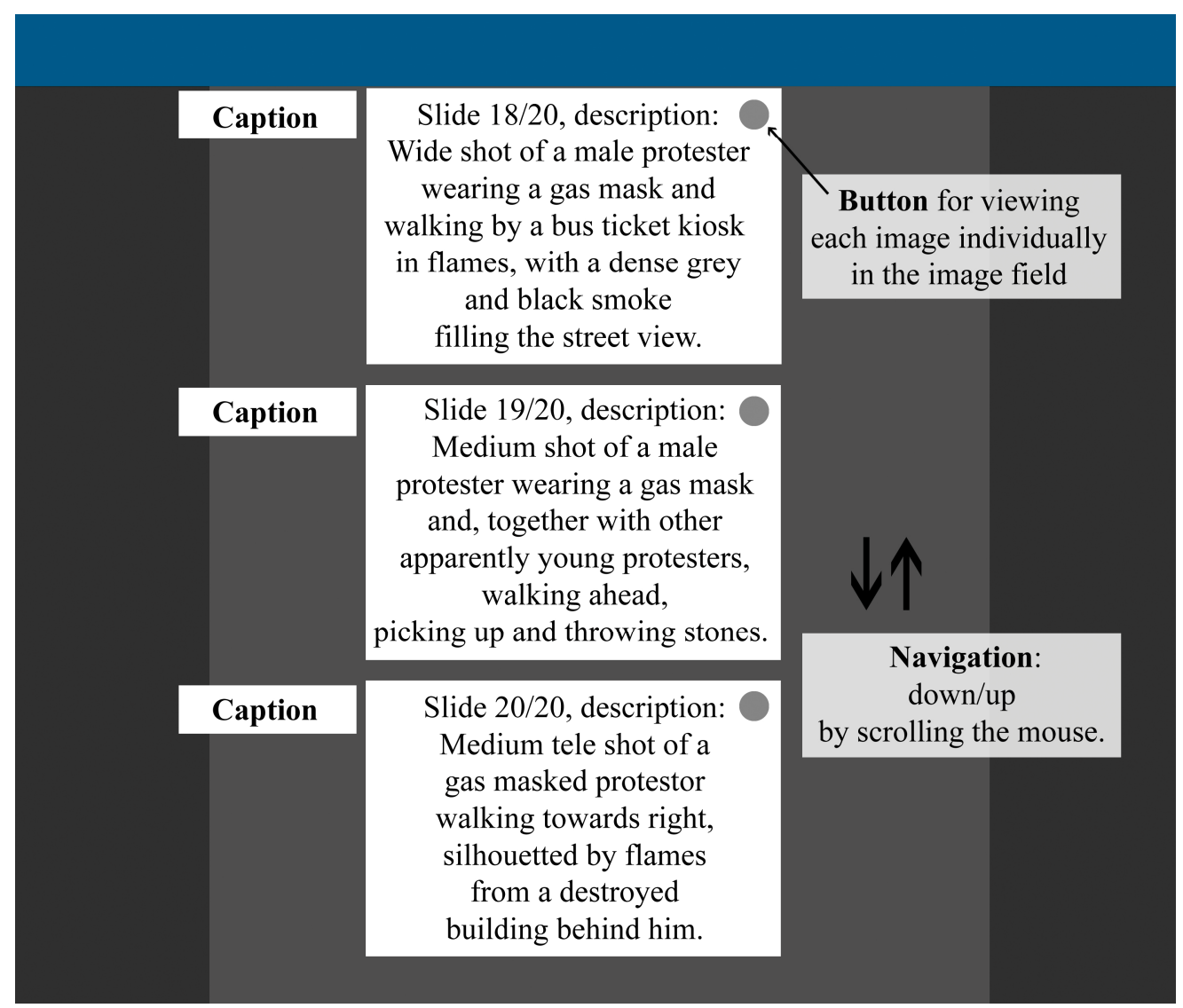

Figure 4. Layout structure of the Guardian picture gallery, images 18-20/20.

The conceptual scene of the picture gallery is again the binary construction within democracy in Greece: while the decision makers, though totally invisible in the visuals, are voting for the bailout deal and the austerity measures, the indignant citizens are demonstrating at Syntagma Square and in the streets of Athens nearby the Parliament, the visual spatial scene of the narrative. The main characters, groupings and their defined identities are: (1) the angered citizens as demonstrators and protesters challenging and attacking the established prevailing order, and (2) the riot police, representing and defending the authority, legislators and decision makers (caption, image 10/20: "Protesters throw Molotov cocktails towards riot police officers guarding the Greek parliament building”).

The majority of the visual material (images 9, 11, 12, 13, 16, 18, 19, 20/20), depict the members of the public as rioters, and their practices as violence, representing them as clashing with the police “...during riots that followed a peaceful march on the first day 
of a 48-hour strike by workers' unions in Athens" (caption, image 13/20). There is, again, little indication of the motivations and demands of the demonstrators, apart from a fleeting notion of the two-day general strike, “...in an all-out effort to block an austerity bill that parliament must pass this week to forestall a state bankruptcy" in the caption of the first image (1/20).

Regarding the mental constituent and the justification of civic practices, the news text does not offer any communicative space for the protesters to express themselves, nor does it give any information on their backgrounds or motives. Two photographs, in particular, serve as examples of inadequate verbal messaging. Image 6/20 presents an aerial, overall view of a peaceful mass-demonstration, with demonstrators filling Syntagma square holding banderoles with written slogans, and supposedly chanting slogans as well, while the caption merely repeats the manifest content of the picture: "People walk past parliament during an anti-austerity rally in Syntagma square." Image $7 / 20$, in turn, focuses on a woman chanting a slogan in front of other demonstrators, while the caption remarkably fails to add any argumentative content to the picture: " $A$ woman shouts slogans at the Syntagma square rally." Furthermore, the news narrative does not discuss the broader goals and meanings of the demonstrations or the values behind them, and thus fails to build understanding and trust toward the demonstrators as co-citizens. Thus, the mental constituent is again affectively biased and ignores the argumentative dimension of civic voice.

When combined, the emotional, affective emphasis of the photographs in the Guardian picture gallery, the dismissal of the articulated messages of the demonstrators, the suggested sequentiality, and the visual intensity, evoke, to a certain extent, a coherent storyworld and intensify the episodic mode of the news text. The episodic approach of the Guardian news text chooses to focus on violent, visually impressive action and the heightened emotions fueling it. Instead of discussing any issues behind the motives of civic action, the news text lacks an analysis of the circumstances from where the civic indignation rises. Thus, the news text seems to lack any components and features of a thematic approach, and builds merely on the episodic mode, creating a strong visual drama. 


\section{Discussion of key findings}

In this section, we draw attention to three sets of communicative practices in captioned photo galleries that have implications for civic voice. First, we discuss the role of "pregnant" photographs and meaning contamination. Second, we address the practice of muting voice through simplified groupings of characters and inadequate verbal messaging. Third, we discuss how a fit or misfit between horizontal/vertical layout and the sequential organization of a narrative may affect the seductiveness of the narrative structure.

\section{Photographs as semiotic resources in constructing editorial reality}

The photo galleries that we studied are typically compiled of individual, de- and recontextualized stock photos, which are taken by several photographers and organized into a narrative whole through a journalistic process. It seems that, in accordance with classical news values of, for instance, conflict, intensity, and unexpectedness (see volume introduction), the galleries tend to favor the selection of dramatic, open-ended and "pregnant" photographs, which depict decisive moments and "offer a window on the preceding and following actions" (Ryan 2014). Our study indicates that such photographs, especially when loosely and vaguely captioned, are powerful resources for imposing a strong internal narrative structure.

Moreover, the incompleteness of meaning and the intensity of the decisive moments that news photographs often depict, make them potential sources of meaning contamination. In the picture galleries of the demonstrations in Athens, this means that the dominating imagery of violent rioting shapes the interpretation of also the less dramatic pictures, thereby constructing an overall message of fear, anger and violence, or the looming uncertainty of ill-defined threat (Massumi 2010). Meaning contamination thus makes intensive pregnant photographs powerful resources for creating "editorial reality", where individual images appear merely as functions of the dramatized whole and tend to lose their referential connection to the real. 
Overall, the captioned photo galleries that we analyzed thus seem to melt the individual photographs, from various events, from different sources and by different photographers, into one solid and firm storyworld. By doing so, they tend to instrumentalize the objects depicted in the images: the various forms and practices of civic action, and the citizens with varied messages and reasoning behind their action, who appear mainly as "characters" serving the narrative entity. In other words, our study indicates that in the multisemiotic interaction of the narrative whole of the captioned slide shows, individual photographs tend to lose part of the referential nature with the events and people they represent. Within news reporting, this kind of narrative independency, where narrative functionality of the images outweighs their gravitation to "real", can be considered problematic.

\section{Simplified groupings, assimilation, and lack of identification}

The visual news texts that we analyzed display a very limited set of characters, and organize them basically into two broad, opposing categories: protesting citizens and governmental/state authority. This binary grouping is produced both through the vocabulary of confrontations and clashes, and through visual framings that juxtapose protesters and the riot police. This simplified grouping is supported by notable lack of identity markers and verbal messaging, concerning the backgrounds and motives of depicted participants. Together with the contaminating potential of the dramatic riot pictures, these practices work as a resource for assimilation, where demonstrators are equated with rioters and civic protests with violence.

Ideally, in multimodal news reporting, visual images and verbal messaging complement each other in the intersemiosis - in the interaction of semiotic choices, and the semantic expansions in multimodal news texts - evoking emotions as well as offering logicodeductive clues. However, in the visual news texts that we analyzed, the verbal captions are typically cut to the minimum and settle for only repeating the most obvious content of the photographs, as the example of "woman shouts slogans" (The Guardian, image $7 / 20$ ) illustrates. As a rule, the texts that we analyzed do not identify the people they depict, e.g. through naming or associating them with a specific group, nor specify the arguments and opinions they have gathered to express in public. In the most extreme 
cases there are no identity markers visible, as a citizen may appear, for example, as a mere silhouette against fire or smoke.

Overall, the visual news texts that we analyzed largely fail to address the premises and goals of civic action - the collective reasoning behind the banderoles. The practice of silencing or muting citizen voice through inadequate messaging is, however, not inherent to the form of the photo gallery, given that written captions do exist and could very well be used to identify and give voice to participants. However, the lack of contextualizing and identifying information is likely to reflect, at least partly, the conventionalized journalistic practices of compiling photo galleries and slide shows, such as separating images from their makers and the context of their making (Bock 2012). In this sense, inadequate identification is inherent to the genre of photo galleries, and may be considered one of its shortcomings with reference to offering possibilities for civic voice.

\section{The fit between layout and narrative flow}

The photo galleries and slide shows that we analyzed invite diachronic, sequential reading through both verbal and visual temporal cues. By doing so, we argue, they foreground episodic, event-oriented framings, where impressive sceneries of protesting citizens receive more news space than "discussions of the economic and political grievance" (Iyenagar, 1991:15), or solution orientated reasoning and arguments by the citizens.

However, we also found important differences between the two texts. Specifically, we argue that the horizontal layout of the New York Times slideshow creates a particularly neat and comfortable fit with a sequentially flowing narrative, thereby increasing "narrative necessity and seduction" that "preempts momentarily the possibility of any but a single interpretation" (Bruner 1991:9). By contrast, the vertical, top-to-bottom organization of the Guardian gallery seems to create a partial misfit, disrupting to some extent the familiar way of looking (de Goede 2015) and thereby reducing the narrative flow. 
Consequently, the top-to-bottom organization of the picture gallery by the Guardian seems narratively more open, transparent and flexible. We would like to suggest that through loosening the narrative grip, it creates increased possibilities for deepening the thematic - argumentative, contextualizing - aspects of the news, albeit this potential is not fully realized in the gallery that we analyzed. Nevertheless, compared with the predecided order of a click-to-proceed and left-to-right layout, the vertical design lays out the photographs on one flat, two-dimensional scroll-down page, which supports the perception of the gallery as a whole and enables more reader-driven control in the order of viewing.

\section{Summary: Muted moments of civic culture}

From the perspective of "doing crisis", our analysis gives rise to the question: What exactly is the crisis depicted in these multimodal news texts? We started with the assumption that the texts deal with a financial or debt crisis facing Greece and Greek citizens. However, through the use of standard crisis markers and imagery, such as fire, smoke, and violence, what is depicted in the media texts seems more like a typification of crisis (as social failure or disruption), deprived of local specificity and particularity. If there is a financial crisis, for example, in the sense of economic hardship or bleak outlook for ordinary citizens, this is not the message of the photo galleries that we analyzed. If there are attempts to find relief to such crisis through civic action beyond street-level protests, these are even less visible.

Overall, our analysis indicates that the combination of strong narrative structure, dramatic imagery, a simplified set of characters, and minimal messaging makes captioned photo galleries and slide shows, as a genre, vulnerable to intervention by culturally dominant master narratives. In our case, the "meaning" of the story, which is strongly implied by the elements and organization of the visual news texts, is easily colonized by the dualistic master narrative of neutral financial pragmatics versus emotionalized politics of anti-austerity movements (Žižek 2010), which, in turn, is rooted in the voice-denying project of neoliberalism (Brown 2005, Couldry 2010). In accordance with neoliberal rationality, civic contribution is essentially "calculated" as 
having no "market value" in these muted representations, which fail, or refuse, to mediate citizens' voices.

\section{Conclusion: Space for voice}

In this concluding section, we look forward by considering ways to unleash the unrealized potential of multimodal news narratives: How could the media do crisis better, in a way that would facilitate civic voice and culture instead of voyeurism?

In principle, we argue, multimodal news texts such as captioned picture galleries and slide shows, journalistic photo novellas, hold potential for multifaceted and nuanced doing of crisis. However, in order to realize this potential, they need to expand on their use of verbal as well as spatial and temporal resources, and their interplay.

We suggest that a key aspect to be enhanced is the interplay of episodic and thematic framing, which optimally facilitates a productive combination of narrative and paradigmatic reasoning. This interplay can be supported in multimodal news narratives by providing additional narrative paths, directions, rhythm and tempo, to complement the traditional left-to-right (or top-to-bottom) progression. Below, we consider three tentative augmented orchestrations of this kind: (1) reverse narrative, (2) 3-D or multidirectional narrative arch, and (3) slow-motion replay. Through supplementing the basic sequential flow, these expansions create space for both personification and politicization, ideally providing glimpses to the background and reasoning for civic action as well as to the structural preconditions and characteristics of crisis. 


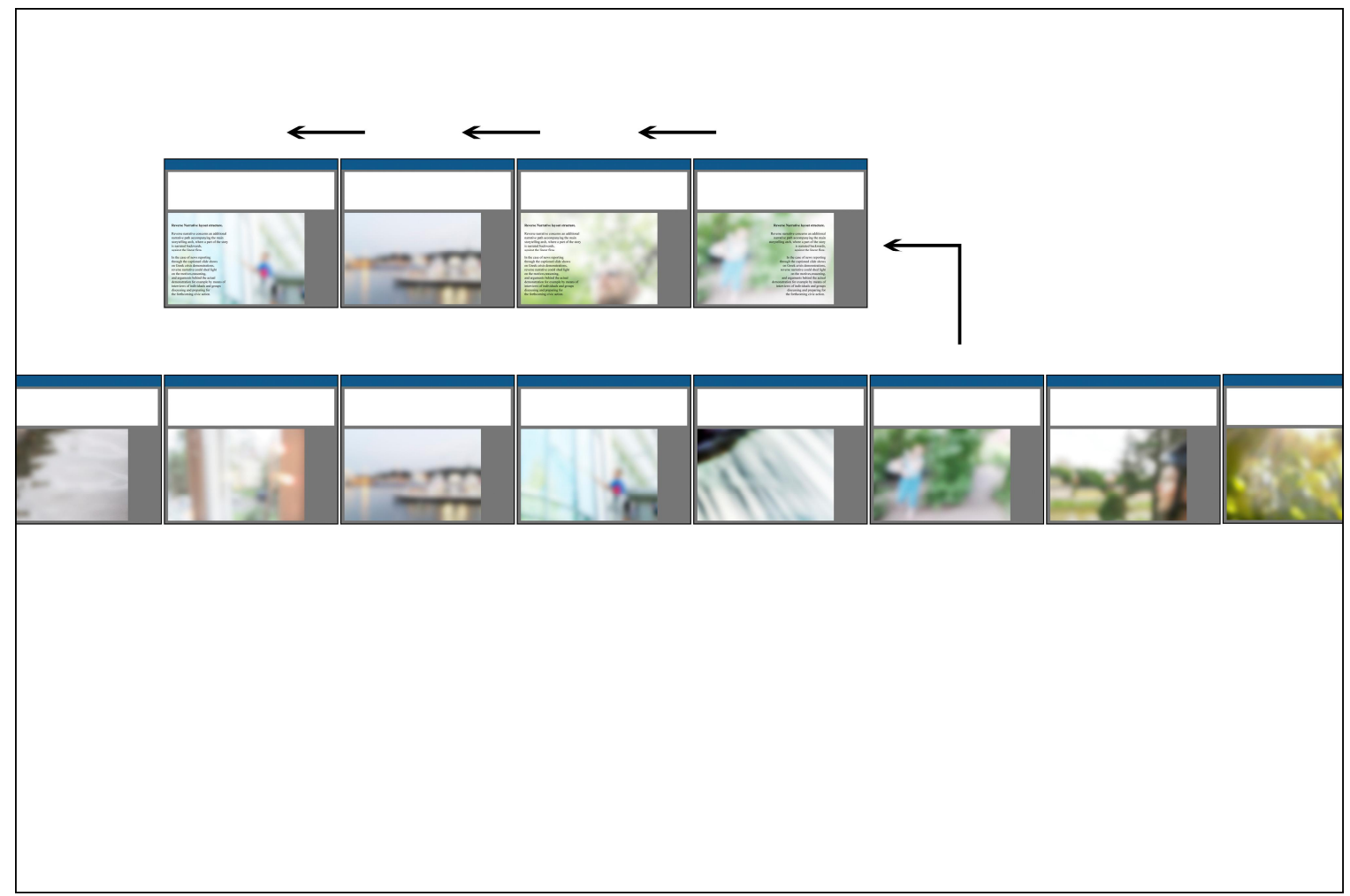

Figure 5. Reverse Narrative layout structure

(1). Reverse Narrative layout structure. Reverse narrative concerns an additional narrative path accompanying the main storytelling arch, where a part of the story is narrated backwards, against the linear flow. In the case of news reporting through the captioned slide shows on Greek crisis demonstrations, reverse narrative could shed light on the motives, reasoning, and arguments behind the actual demonstration for example by means of interviews of individuals and groups discussing and preparing for the forthcoming civic action. Moreover, such reverse storytelling paths would enable proper identification and personification of people as well as the various groups participating in demonstrations. 


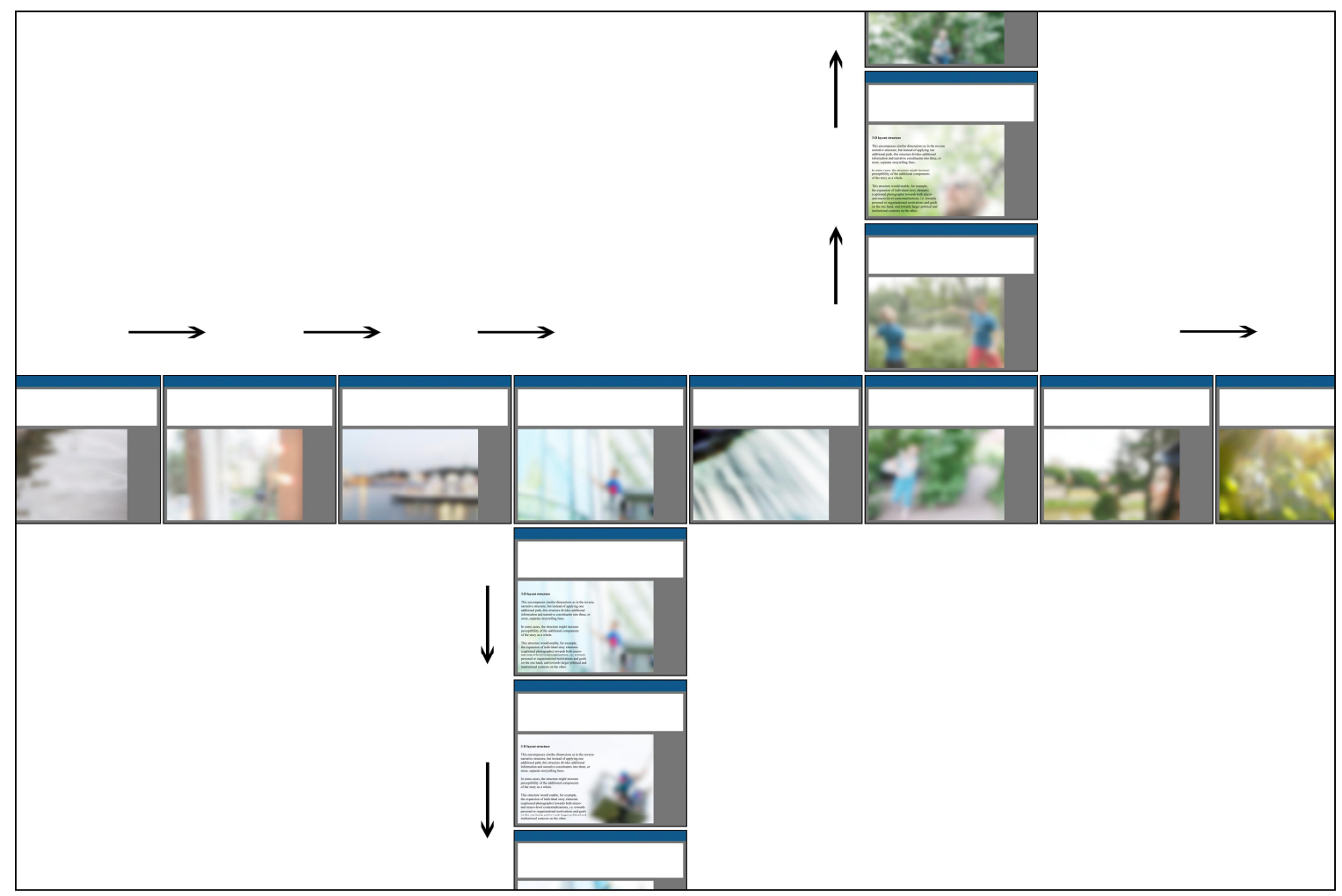

Figure 6. 3-D layout structure

(2) 3-D layout structure. This encompasses similar dimensions as in the reverse narrative structure, but instead of applying one additional path, this structure divides additional information and narrative constituents into two, or more, separate storytelling lines. In some cases, the structure might increase perceptibility of the additional components of the story as a whole. This structure would enable, for example, the expansion of individual story elements (captioned photographs) towards both micro- and macro-level contextualizations, i.e. towards personal or organizational motivations and goals on the one hand, and towards larger political and institutional contexts on the other. 


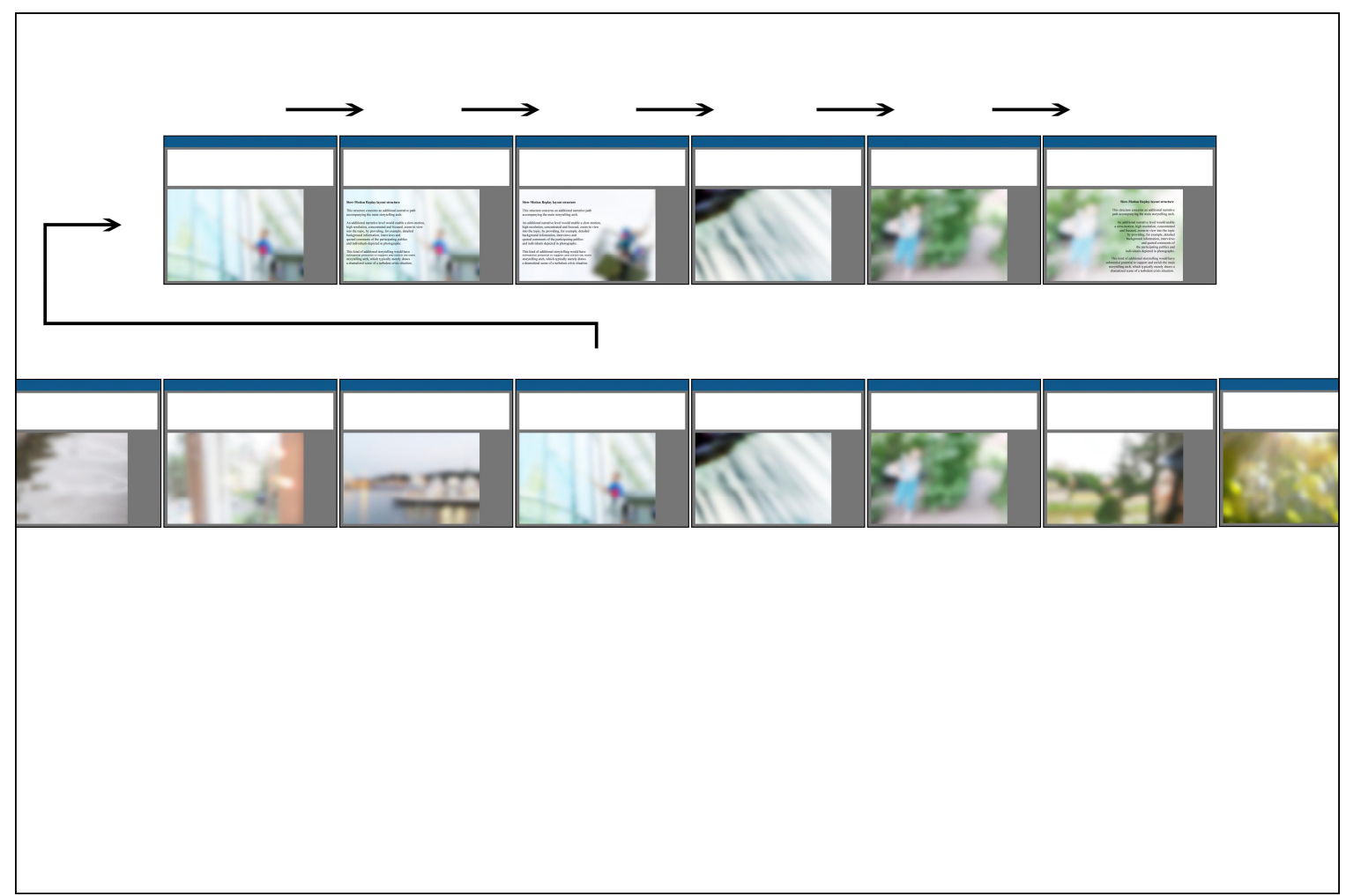

Figure 7. Slow-Motion Replay layout structure

(3) Slow-motion replay layout structure. This structure concerns an additional narrative path accompanying the main storytelling arch. An additional narrative level would enable a slow-motion, high resolution, concentrated and focused, zoom-in view into the topic, by providing, for example, detailed background information, interviews and quoted comments of the participating publics and individuals depicted in photographs. This kind of additional storytelling would have substantial potential to support and enrich the main storytelling arch, which typically merely draws a dramatized scene of a turbulent crisis situation.

In summary, as we have illustrated, the picture galleries and slide shows that we analyzed in this study offer little to no space for civic voice. It may be argued that without additional narrative paths and dimensions, these presentations tend to undermine many of the preconditions of civic culture as defined by Dahlgren (2009:108): they trivialize or invalidate demonstrations as a practice of civic culture, and distort both the individual and civic identities of the participating publics through muting their arguments and using them as an assimilated category of characters in the dualistic narrative. 
Furthermore, they have limited capacity in both representing communicative spaces - as the focus on street-level action hides from view all other spaces of civic action - and offering them for civic interaction. In terms of creating and disseminating knowledge, they tend to simplify and distort social debates and grievances through focusing on front line action and ignoring the multifaceted grounding of civic action and the diversity of reasoning behind it. Finally, the narratives told by the photo galleries seem to suggest the inflation of rhetorical and democratic values by focusing on the disruptive and violent events, while failing almost completely to address the rich set of values underlying the moral concerns that motivate civic action in the first place. For these reasons, we argue, they are unlikely to build horizontal trust (Dahlgren 2011:21) among members of the public throughout Europe. It may even be argued that such stories contribute, by contrast, to building a firewall between the austerity zone and the rest of Europe, strengthening the prevailing binary oppositions between us and them, North and South, morality and brinkmanship, and between allegedly logical, rational necessity and emotioned, ideological populism. Instead of valuing and supporting civic voice, these narrative presentations seem to treat it as an aesthetic soundscape for coloring the dualistic debt crisis drama.

Ideally, the augmented, narratively diverse and multidimensional layout structures that we proposed can offer more space for civic voice and contribute to the construction and implementation of civic culture. These kinds of add-on storytelling paths and narrative structures explicitly support a more multifaceted representation and enactment of identities and civic practices. Implicitly, they also have an increased potential for supporting the construction of layered knowledge and diversity of argumentation, and the expression and assessment of cultural and community values. In this way, this kind of reorganization and augmentation of both the episodic and thematic components of narration into news storytelling offers significant potential for unfolding the simplifying binary constructions that frequently frame the debt crisis discourses. 


\section{Links}

The Guardian. 2011. "Violence erupts as Greece strike begins - in pictures." http://www.theguardian.com/world/gallery/2011/oct/19/greece-protest

The New York Times. 2011. "Clashes as Greek government passes austerity measures." http://www.nytimes.com/slideshow/2011/06/29/world/europe/20110630-GREECE7.html?_r=1\&

\section{References}

Abbott, H. Porter. 2008. The Cambridge Introduction to Narrative. Cambridge, UK: Cambridge University Press.

Block, Bruce. 2008. The Visual Story: Creating the Visual Structure of Film, TV and Digital Media. Amsterdam: Elsevier Focal Press.

Bock, Mary A. 2012. "Newspaper Journalism and Video: Motion, Sound, and New Narratives." New Media \& Society 14 (4): 600-616. doi:10.1177/1461444811421650.

Brown, Wendy. 2005. Critical Essays on Knowledge and Politics. Princeton, NJ: Princeton University Press.

Bordwell David, and Kristin Thompson. 2001. Film Art: An Introduction. New York: McGraw-Hill.

Bruner, Jerome. 1986. Actual Minds, Possible Worlds. Cambridge, MA: Harvard University Press.

Bruner, Jerome. 1990. Acts of Meaning. Cambridge, MA: Harvard University Press.

Bruner, Jerome. 1991. "The Narrative Construction of Reality." Critical Inquiry 18 (1): $1-21$.

Couldry, Nick. 2010. Why Voice Matters: Culture and Politics After Neoliberalism. Los Angeles, CA: Sage.

Dahlgren, Peter. 2000. "The Internet and the Democratization of Civic Culture." Political Communication 17 (4): 335-340. doi:10.1080/10584600050178933.

Dahlgren, Peter. 2009. Media and Political Engagement: Citizens, Communication, and Democracy. New York, NY: Cambridge University Press.

Dahlgren, Peter. 2011. "Young Citizens and Political Participation: Online Media and Civic Cultures." Taiwan Journal of Democracy 7 (2): 11-25.

Goodwin, Jeff, James M. Jasper, and Francesca Polletta. 2007. "Emotional Dimensions of Social Movements." In The Blackwell Companion to Social Movements, ed. by David A. Snow, Sarah Soule, and Hanspeter Kriesi, 413-432. Malden, MA: Blackwell. 
de Goede, Marieke. 2015. "Documenting Financial Assemblances and the Visualization of Responsibility." In Documenting World Politics: A Critical Companion to IR and Non-Fiction Film, ed. by Rens Van Munster, and Casper Sylvest, 58-77. New York, NY: Routledge.

Herman, David (ed). 2007. The Cambridge Companion to Narrative. Cambridge, UK: Cambridge University Press.

Iyengar, Shanto. 1991. Is Anyone Responsible? Chicago, IL: University of Chicago Press.

Lehman, Susan. 2015. "Reading The Times With Paul Butler." International New York Times, February 26, 2015.

http://www.nytimes.com/times-insider/2015/02/26/reading-the-times-with-paul-butler/

Massumi, Brian. 2010. "The Future Birth of the Affective Fact. The Political Ontology of Threat." In The Affect Theory Reader, ed. by Melissa Gregg, and Gregory J. Seigworth. 52-70. Dunham, NC: Duke University Press.

Matthiessen, Christian. 2006. "The Multimodal Page: A Systemic Functional Exploration." In New Directions in Multimodal Discourse Analysis, ed. by Wendy Bowcher, and Terry Royce, 1-62. Hillsdale, NJ: Lawrence Erlbaum Associates.

Olsson, Eva-Karin, and Lars W. Nord. 2015. "Paving the Way for Crisis Exploitation: The Role of Journalistic Styles and Standards.” Journalism 16 (3): 341-358.

Page, Ruth. 2011. "Introduction". In New Perspectives on Narrative and Multimodality, ed. by Ruth Page, 1-13. New York, NY: Routledge.

Pew Research Center. 2014. State of the News Media 2014.

http://www.journalism.org/packages/state-of-the-news-media-2014/

Ryan, Marie-Laure. 2007. "Toward a Definition of Narrative." In The Cambridge Companion to Narrative. ed. by David Herman, 22-35. Cambridge, UK: Cambridge University Press.

Ryan, Marie-Laure. 2014. "Narration in Various Media." In The Living Handbook of Narratology, ed. by Peter Hühn, et al. Hamburg, Germany: Hamburg University. http://www.lhn.uni-hamburg.de/article/narration-various-media

Somers, Margaret R., and Gloria D. Gibson. 1994. "Reclaiming the Epistemological "Other": Narrative and the Social Constitution of Identity." In Social Theory and the Politics of Identity, ed. By Craig Calhoun, 37-99. Oxford, UK: Blackwell.

Tsoukala, Philomila. 2013. "Narratives of the European Crisis and the Future of (Social) Europe." Georgetown Public Law and Legal Theory Research Paper No. 13-012. 
Van Dijk, Teun A. 2001. "Critical Discourse Analysis." In The Handbook of Discourse Analysis, ed. by Deborah Schiffrin, Deborah Tannen, and Heidi E. Hamilton, 352-371. Oxford, UK: Blackwell.

Žižek, Zlavoj. 2010. “A Permanent Economic Emergency.” New Left Review 64: 85-95.

YLE 2015. Morning tv (Aamu-tv), the morning news show of the Finnish Broadcasting Company Yle. March $5^{\text {th }} 2015$.

http://yle.fi/uutiset/katainen_sotesta_poliitikoille_kunnallinen_itsehallinto_peruspalveluj a_tarkeampaa/7846613. 